\title{
Source Areas, Drainage Density, and Channel Initiation
}

\author{
David R. Montgomery and William E. Dietrich
}

Department of Geology and Geophysics, University of California, Berkeley

\begin{abstract}
An analysis of channel head locations provides insight into controls on drainage density, the response of landscapes to climatic change, and the delineation of source areas for channel network simulations. Channel heads and colluvial deposits were mapped in a roughly $2 \mathrm{~km}^{2}$ area near San Francisco, California, and, although channel heads are located within colluvial deposits in hollows, many such deposits do not support channel heads. Channel heads were classified as either gradual or abrupt. For either type of channel head, the channel reach immediately downslope may be contiguous with the channel network or may consist of a series of short discontinuous channel segments. The local valley slope at the channel head is inversely related to both source area and source-basin length as well as to the contributing area per unit contour length at the channel head. In contrast, valley slope does not vary with drainage area upslope of channel heads. Field observations and a similarity between predicted and observed area-slope relations suggest that the location of channel heads on steep slopes may be controlled by subsurface flow-induced instability of the colluvial fill. Preliminary field observations also suggest that abrupt channel heads on gentle slopes are controlled by seepage erosion, whereas gradual channel head locations appear to be governed by saturation overland flow. Consideration of the geometric relationship between source areas and the first-order drainages that contain them results in an inverse relation between mean source-basin length and drainage density.
\end{abstract}

\section{INTRODUCTION}

Because the channel head represents a major boundary between hillslopes and channels, the factors governing channel initiation are essential components of quantitative theories for the evolution of both hillslopes and drainage networks. Although many properties of channel networks can be predicted by the random topology model of Shreve [1966], for quantities such as drainage density it is necessary to know the number of sources per unit area [Shreve, 1969], a property that the topology does not predict. Physically based theories for predicting the source areas contributing to channel heads will consequently contribute to network models and provide a linkage between hillslope processes and network properties.

In humid environments, channels generally begin in unchanneled valleys or hollows (Figure 1) [Hack and Goodlett, 1960; Hack, 1965; Dietrich et al., 1986; Montgomery and Dietrich, 1988a]. Channels differ from hollows in that they have well-defined measurable banks and the channel head represents the transition from the unchanneled hollow to the channel network. Like channels, hollows typically form branching networks; only a portion of the hollows in an area terminate at the tips of channels [Hack, 1965; Dietrich et al., 1987].

Channel head locations are controlled by the competing influences of fluvial transport in channels and diffusional hillslope transport processes which concentrate colluvium in hollows and tend to infill channels. Colluvium eroded from adjacent ridges and sideslopes slowly accumulates in hollows until it is relatively rapidly discharged by landsliding or gullying [Dietrich and Dunne, 1978]. During discharge events, channel heads may advance great distances upslope and then retreat downslope as the hollow refills with collu-

Copyright 1989 by the American Geophysical Union.

Paper number 89 WR00843.

0043-1397/89/89WR-00843\$05.00 vium [Dietrich et al., 1987]. In areas where the age of the basal colluvium has been determined at several points along the hollow axis [Reneau, 1988] the upslope excursions of the channel head appear to be short compared to the intervening periods of accumulation; hence channel heads may remain in stable locations for long periods.

To our knowledge, however, no quantitative predictions of specific channel head locations have been attempted for landscapes where Horton overland flow [Dunne, 1978] is rare. Instead, three general processes have been hypothesized as contributing to channel initiation: incision by saturation overland flow [Kirkby and Chorley, 1967], seepage erosion [Dunne, 1980], and shallow landsliding [Dietrich et $a l ., 1986]$. Saturation overland flow is probably most important on gentle slopes, whereas seepage erosion and landsliding should predominate on steep slopes where saturation overland flow is rare or absent. None of these mechanisms are well-documented, however, and surprisingly few field data exist on the location of channel heads [Morisawa, 1957; Coates, 1958; Maxwell, 1960; Mark, 1983; Dietrich et al., 1986, 1987; Montgomery and Dietrich, 1988a].

The landslide channel-initiation theory proposed by Dietrich et al. [1986] predicts a decrease in source length with increasing hollow gradient. Although they reported data that support the general inverse form of the predicted relation, the data were not sampled systematically and represent a limited range of slopes. Here we supplement those initial observations with the results of a channel head location survey conducted near San Francisco, California. We also extend the theory of Dietrich et al. [1986] to predict source area and find that it accords with the general trend of the field observations. Finally, we examine the geometric relationship between source areas and first-order drainage basins and obtain a general expression for drainage density as a function of source-basin geometry and network morphometric parameters that is well approximated by the reciprocal of the source-basin length, which accurately predicts the observed drainage density of the study area. 


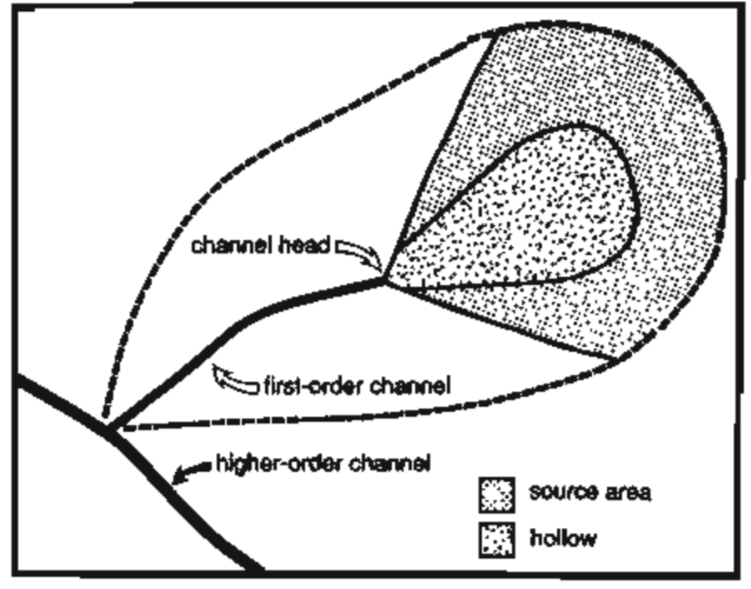

Fig. 1. Idealized relations between a hollow, a source area, and the related first-order basin. Although hollows are typically zones of colluvium deposition, colluvial deposits are not always coincident with the hollow nor entirely within the source area.

\section{Theory For ChANNel INITIATION By LANDSLIDING}

Dietrich et al. [1986) proposed that on steep hillslopes, channel head locations are maintained by recurreat landslides that remove a small amount of the accumulated colluviun in hollows. To predict channel head location, they coupled the infinite slope stability model with a model for predicting convergence-induced pore pressures. This coupled model predicts an inverse relationship between the length of hillslope above a channel head and the local valley gradient at the channel head and can be modified to predict source area rather than source-basin length.

The model for the convergence of subsurface flow [Iida, 1984] assumes colluvium with uniform, isotropic hydraulic conductivity overlying impermeable bedrock. Wilson et al. [1987] have shown, by comparison with a numerical model, that the prediction of pore pressures by this model, though crude, is approximately correct. Wilson and Dietrich [1987] also showed that, even though the colluvium-bedrock boundary cannot be strictly considered as impermeable, its associated conductivity contrast is several orders of magnirude. Because the hydraulic conductivity of colluvium in hollows also tends to decrease with depth [Wilson and Dietrich, 1987] and the conductivity of even relatively homogeneous natural materials tends to be nonuniform [Freeze, 1975], this model is at best an approximation.

In Iida's [1984] model, the water discharge $Q$ per unit contour length is taken as equal to a constant rainfall rate $R_{\mathrm{o}}$ multiplied by the contributing area per unit contour length $a(t)$ which with increasing time $t$ expands upslope from the source; thus

$$
Q(t)=R_{0} a(t)
$$

According to Darcy's law, the horizontal component of the flow per unit contour length for a depth of saturation $h$ measured vertically is given by

$$
Q(t)=h(t) K \sin \theta \cos \theta
$$

where $K$ is the hydraulic conductivity of the soil when saturated and $\theta$ is angle of inclination of the hillslope. Combining these equations yields

$$
h(t)=\frac{R_{0} a(t)}{K \sin \theta \cos \theta}
$$

Dietrich et al. [1986] reasoned that the contributing area equals the entire upslope area $A$ and they argued that the width of the colluvial deposit at the channel head $W_{h}$ defines the contour length through which the subsurface runoff from the source area must travel. Hence they proposed setting

$$
a(T)=A / W_{h}
$$

where $a(T)$ is the contributing area per unit contour length for channel-maintaining events. Alternatively, drainage induced by an incised channel head may draw the flow lines toward the channel head, in which case

$$
a(T)=A / W_{c h}
$$

where $W_{c h}$ is the width of the channel head. At present, we have neither field observations nor theoretical reasons to prefer either (4) or (5).

For cohesionless soils, the infinite slope stability model [e.g., Selby, 1982] says that at failure

$$
\rho_{s} z \tan \theta=\left(\rho_{s} z-\rho_{w} h\right) \tan \phi
$$

where $\rho_{s}$ and $\rho_{w}$ are the bulk densities of the saturated soil and the water respectively, $z$ is the soil depth measured vertically, and $\phi$ is the angle of internal friction for the soil. For channel maintaining events, substituting (3) into (6) yields

$$
a(T)=\frac{\rho_{s} K z \sin \theta \cos \theta}{\rho_{w} R_{0}}\left[1-\left(\frac{\tan \theta}{\tan \phi}\right)\right]
$$

Equation (7) is valid only when pore pressures are hydrostatic and

$$
\left[\frac{\rho_{s}-\rho_{w}}{\rho_{s}}\right] \tan \phi<\tan \theta \leq \tan \phi
$$

We tested (7) against observations made in the San Francisco Bay area.

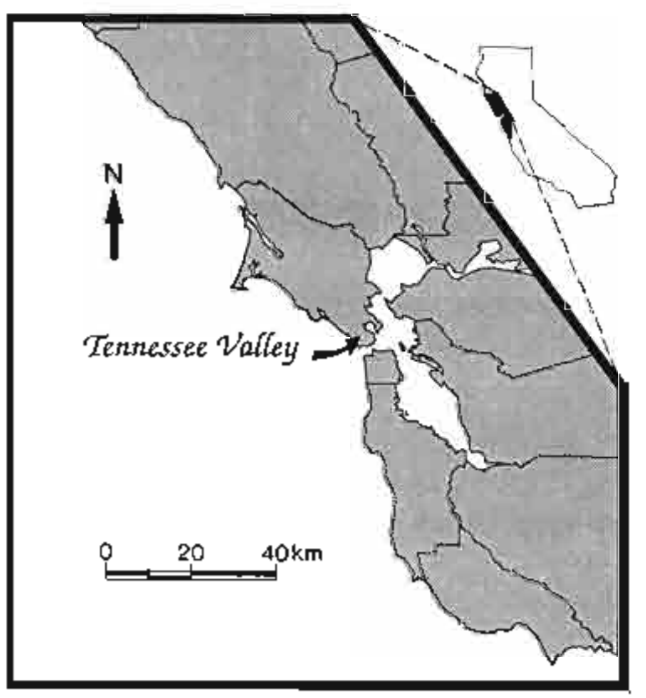

Fig. 2. Location map for the Tennessee Valley study area, coastat central California. San Francisco is located at the northern tip of the peninsula in the center of the map and the lines represent county boundaries. 


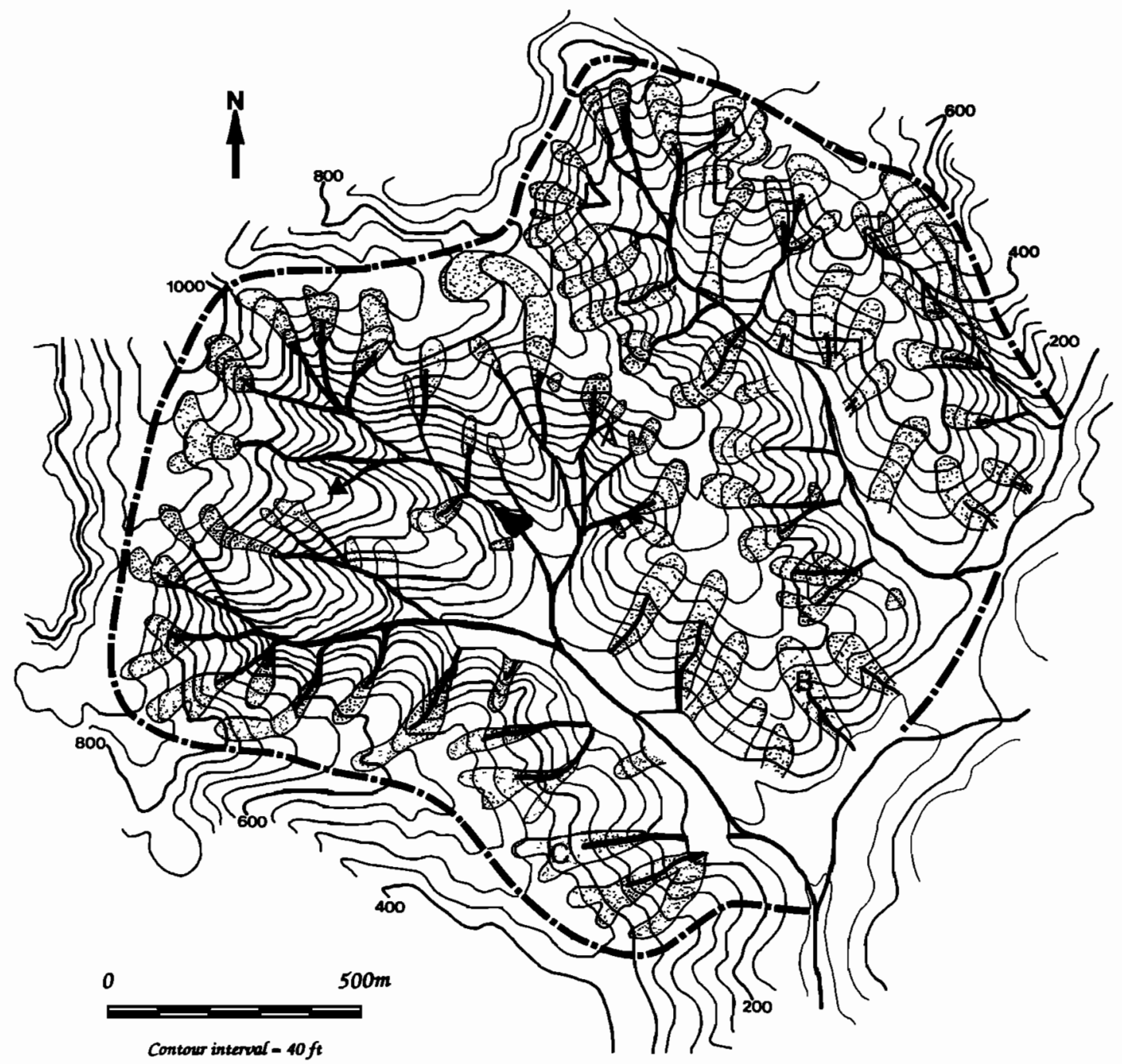

Fig. 3. Channels and colluvial deposits in the study area. Both continuous and discontinuous channels are indicated by heavy black lines and the approximate extent of colluvial deposits are indicated by the stippled areas. Small triangle in middle left of the figure represents a channel head associated with a road drainage culvert. The black pattern in the area near center of figure denotes a man-made pond. Capital letters indicate channel heads shown in detail in Figures $4,5 a$, and $6 a$.

\section{STUdy AREA}

The study area, selected for its broad range of slopes and open grassland vegetation, is located near Tennessee Valley in Marin County, California (Figure 2). It occupies $2.1 \mathrm{~km}^{2}$ on the eastern flanks of Coyote Ridge and contains the headwaters of creeks draining into both the Pacific Ocean and San Francisco Bay (Figure 3). Elevations vary from 61 $m$ in the valleys on the eastern end to $314 \mathrm{~m}$ on Coyote ridge at the western margin of the study site. Local slopes range from $15^{\circ}$ to $30^{\circ}$ in the southeastern half of the study area to $30^{\circ}$ to $40^{\circ}$ with broad ridgetops on the northwestern margin.

The area is underlain by intensely deformed greywacke, chert, and greenstone [Wahrhaftig, 1984] and hillside soils are generally well-drained upland loams, whereas gravelly loams and thick clay loams occupy the larger valleys [U.S. Department of Agriculture, 1985]. The region has a Mediterranean climate with an average annual precipitation of about $760 \mathrm{~mm}[$ Rantz, 1968] and vegetation consists of both native and introduced species. Northern coastal scrub associations, including dense stands of poison oak and coyote bush, occur within many hollows, and coastal prairie associations and European grasses cover many ridgetops and sideslopes. Stands of eucalyptus grow along the stream channels of the larger valleys. Cattle grazing was the primary activity in the area from about 1850 until establishment of the Golden Gate National Recreation Area in 1972.

\section{Methods AND OBSERVATIONS}

Colluvial deposits and channels were mapped in the field onto an enlargement of the U.S. Geological Survey Point Bonita 7.5-min quadrangle (Figure 3). Channel heads were defined as the upslope limit of erosion and concentration of flow within steepened banks. The local slope in the axis of the unchanneled valley immediately above channel heads was measured with a Brunton compass and channel head locations were mapped onto topographic basemaps in the field. For discontinuous channels, the channel head was considered to be the headcut closest to the drainage divide. The approximate boundaries of colluvial fills were also mapped in the field and were based on the topographic 
expression of hollows and exposures in landslide scarps and stream channels.

Shreve [1966, p. 20] defined channel network sources as the "points farthest upstream in a channel network" a definition which, if one considers discontinuous channels as part of the channel network, is synonymous with our use of the term channel head. Shreve [1969] also defined a source area as the drainage area upslope of a channel head. In the discussion that follows, we use these definitions and introduce the term source-basin length for the more subjective length of the source area.

Source areas and source-basin lengths, as well as the width of the depositional zone at each channel head, were measured from field maps using a digital planimeter (Table 1). Source-basin length was defined as the distance from the channel head to the drainage divide measured up the axis of the hollow and source area was defined by boundaries drawn perpendicular to contours. The width of the colluvial deposit was measured perpendicular to the hollow axis at the channel head.

Determining the channel head location was relatively straightforward in many instances but is more subjective where the channel begins gradually. Consequently, we also recognize that no two workers would identify precisely the same channel head location in all cases (as demonstrated by Maxwell [1960]). Some minor error was also likely in both mapping channel head locations onto and measuring the upslope length and drainage area from the relatively undetailed basemap.

Even though some colluvial fills have no topographic expression, a topographic break in slope is common at the margins of colluvial deposits in hollows. Moreover, characteristics of the surface can also generally be used to estimate the depth of fill in unchanneled valleys [Dengler and Montgomery, 1989]. Consequently, although borings or seismic refraction surveying would be desirable, we consider the mapped extent of thick colluvium in hollows to be reasonably accurate.

Twenty-two of the 90 hollows identified in this study had no channel. In the remaining 68 hollows, two general types of channel head were identified and defined as abrupt and gradual. Five hollows where hiking trails concentrate runoff immediately upslope of the channel head were omitted from the analysis. Only a few of the channels in the study area are floored with bedrock. Twenty-seven of the first-order channel segments were discontinuous below their channel heads and seventeen channels terminated in colluvial fans in the wide valleys along the major incised streams.

Examples of channel head types are shown in Figure 4, 5 , and 6. Many of the 35 abrupt channel heads occur within debris flow scarps indicative of recent slope failures (Figure 4). In several of these hollows, scarps of apparently differing ages in the vicinity of the present channel head suggest repeated local instability.

On gentler slopes in the Tennessee Valley area saturation overland flow is common during heavy winter rainstorms and can extend almost the full length of the hollow from the channel head to the drainage divide, as also found in nearby grasslands by Wilson and Dietrich [1987]. Abrupt channel heads formed by steep headcuts (Figure $5 a$ ) that may be incised as much as several meters are common on these gentler slopes. The channels immediately downslope of abrupt channel heads on gentle slopes are generally discon-
TABLE 1. Source Area Data From Tennessee Valley, California

\begin{tabular}{|c|c|c|c|}
\hline $\begin{array}{l}\text { Local Valley Slope } \\
\text { Above Channel } \\
\text { Head, }{ }^{*} \mathrm{~m} / \mathrm{m}\end{array}$ & $\begin{array}{c}\text { Source } \\
\text { Area, } \dagger \\
\mathbf{m}^{2}\end{array}$ & $\begin{array}{c}\text { Source-Basin } \\
\text { Length, } \dagger \dagger \\
\text { m }\end{array}$ & $\begin{array}{l}\text { Width of Colluvial } \\
\text { Fill at Channel } \\
\text { Head, } m\end{array}$ \\
\hline 0.45 & 7,400 & 120 & 60 \\
\hline 0.43 & 12,000 & 180 & 60 \\
\hline 0.49 & 7,900 & 140 & 50 \\
\hline 0.42 & 9,100 & 180 & 60 \\
\hline 0.62 & 2,700 & 50 & 36 \\
\hline 0.78 & 3,800 & 100 & 40 \\
\hline 0.44 & 9,300 & 130 & 5 \\
\hline 0.53 & 3,700 & 80 & 45 \\
\hline 0.55 & 6,700 & 110 & 30 \\
\hline 0.42 & 10,000 & 190 & 5 \\
\hline 0.42 & 7,900 & 160 & 5 \\
\hline 0.47 & 9,900 & 140 & 16 \\
\hline 0.58 & 5,400 & 130 & 8 \\
\hline 0.53 & 2,100 & 100 & 30 \\
\hline 0.51 & 6,100 & 110 & 50 \\
\hline 0.53 & 4,500 & 120 & 32 \\
\hline 0.60 & 4,900 & 80 & 20 \\
\hline 0.44 & 8,500 & 120 & 60 \\
\hline 0.47 & 9,800 & 160 & 28 \\
\hline 0.44 & 5,500 & 100 & 28 \\
\hline 0.62 & 4,300 & 100 & 20 \\
\hline 0.34 & 8,200 & 160 & 32 \\
\hline 0.57 & 8,000 & 110 & 16 \\
\hline 0.65 & 2,600 & 50 & 50 \\
\hline 0.24 & 40,100 & 400 & 28 \\
\hline 0.58 & 8,900 & 140 & 12 \\
\hline 0.49 & 14,500 & 150 & 48 \\
\hline 0.58 & 8,400 & 90 & 48 \\
\hline 0.38 & 15,100 & 150 & 43 \\
\hline 0.36 & 9,300 & 120 & 28 \\
\hline 0.36 & 8,300 & 120 & 32 \\
\hline 0.58 & 6,300 & 160 & 40 \\
\hline 0.44 & 4,200 & 120 & 24 \\
\hline 0.55 & 5,400 & 140 & 24 \\
\hline 0.47 & 11,400 & 120 & 48 \\
\hline 0.67 & 5,200 & 120 & 30 \\
\hline 0.42 & 7,200 & 100 & 44 \\
\hline 0.40 & 11,900 & 150 & 32 \\
\hline 0.81 & 4,900 & 90 & 28 \\
\hline 0.51 & 3,800 & 80 & 5 \\
\hline 0.34 & 11,400 & 170 & 48 \\
\hline 0.25 & 14,900 & 170 & 56 \\
\hline 0.27 & 14,000 & 190 & 40 \\
\hline 0.36 & 7,500 & 170 & 40 \\
\hline 0.29 & 13,300 & 170 & 52 \\
\hline 0.25 & 24,000 & 190 & 28 \\
\hline 0.45 & 7,400 & 120 & 52 \\
\hline 0.45 & 12,700 & 260 & 8 \\
\hline 0.47 & 4,700 & 110 & 12 \\
\hline 0.36 & 10,700 & 180 & 32 \\
\hline 0.32 & 13,100 & 170 & 28 \\
\hline 0.45 & 4,000 & 90 & 40 \\
\hline 0.30 & 11,000 & 170 & 32 \\
\hline 0.33 & 6,700 & 120 & 24 \\
\hline 0.46 & 3,800 & 80 & 24 \\
\hline 0.84 & 1,800 & 60 & 30 \\
\hline 0.76 & 1,200 & 80 & 20 \\
\hline 0.70 & 6,800 & 140 & 48 \\
\hline 0.91 & 1,200 & 60 & 8 \\
\hline 0.62 & 6,600 & 160 & 8 \\
\hline 0.67 & 5,600 & 110 & 8 \\
\hline 0.45 & 10,800 & 170 & 5 \\
\hline 0.78 & 2,000 & 80 & 5 \\
\hline
\end{tabular}

*Measured with a brunton compass.

$\dagger$ Average value of several measurements rounded to nearest $1 \overline{00}$ $\mathrm{m}^{2}$.

$\dagger \dagger$ Average value of several measurements rounded to nearest 10 m. 
tinuous, with several headcuts separated by small depositional fans. Seepage undermining of the headcut appears to influence the location of many of these channel heads. For example, seepage faces coincident with the top of a recessed basal alcove in the headcut were observed at several channel heads during and after winter storms (Figure $5 b$ ). Saturation overland flow over the lip of the headcut, however, was also observed at several of these channel heads during storms.

Gradual channel heads (Figure $6 a$ ) lack either a distinctive headcut, or evidence of recent slope instability and the channels downslope of them may also be discontinuous. Although the transition from unchanneled valley axis to a

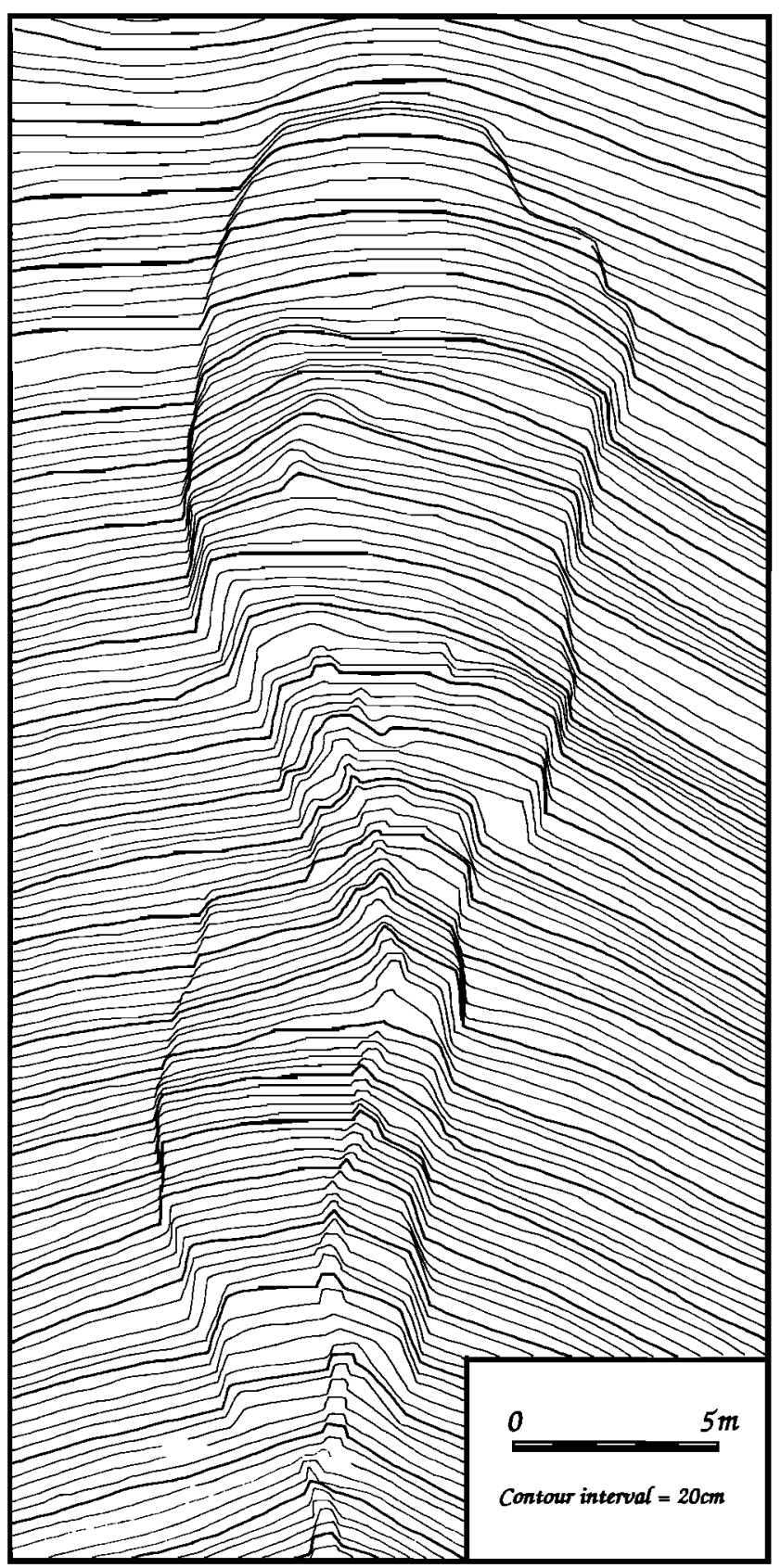

Fig. 4. Topographic map of channel head A in Figure 3. The channel head is located within the higher of the two debris flow scars. Note that the topography is best seen when the figure is viewed from the top of the page. Both the scale and contour interval are identical for the topographic maps in Figures 4, 5, and 6.

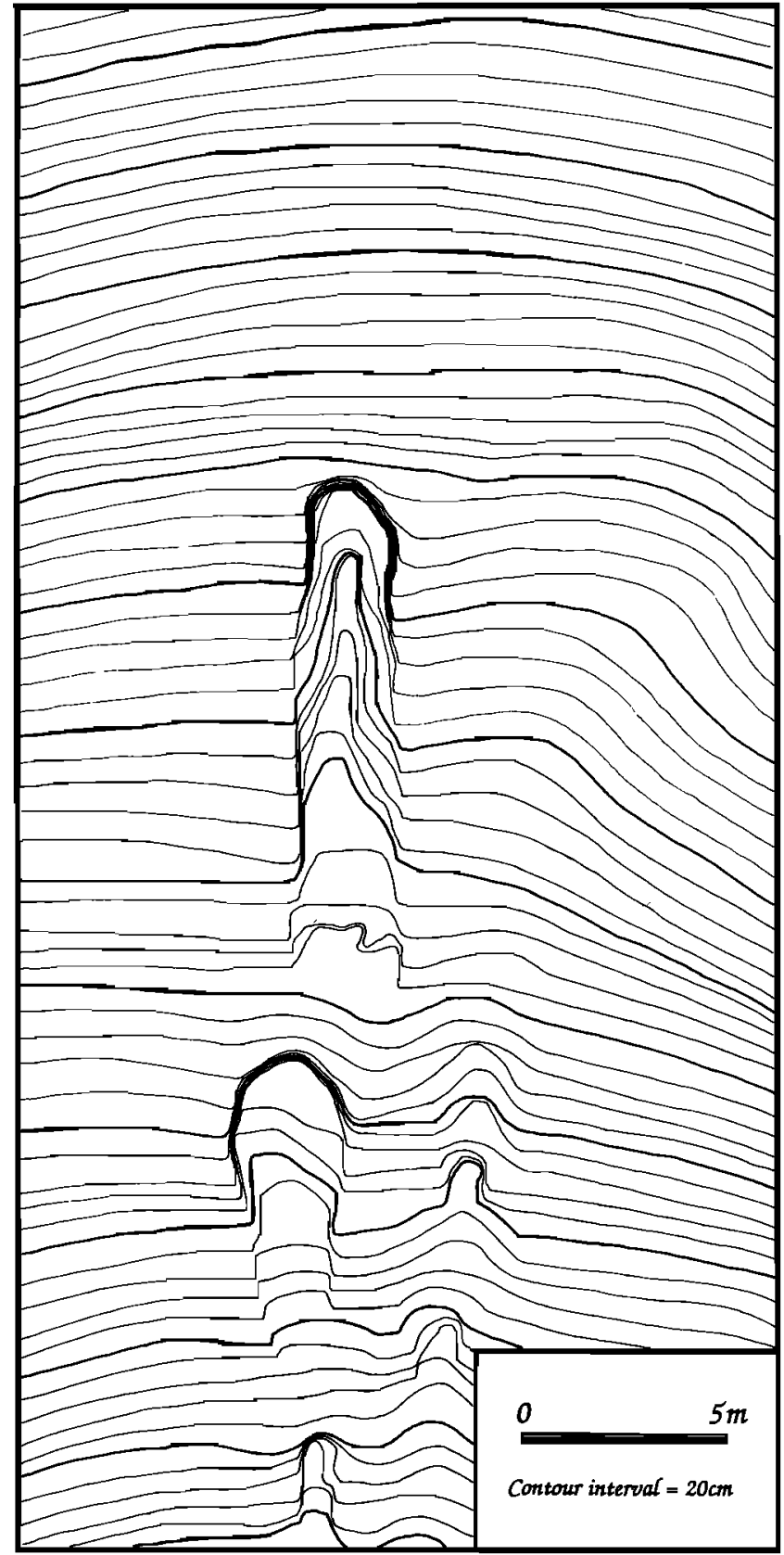

Fig. 5a. Topographic map of channel head B in Figure 3. The channel begins abruptly at the steep headcut in the upper half of the figure and is separated from the lower headcut by an aggraded reach.

channel generally occurs over a short distance, many of these channel heads are difficult to locate precisely because of the ambiguity in defining what constitutes a bank. We have also observed saturation overland flow (Figure $6 b$ ) and evidence of sediment transport at gradual channel heads in this area during winter storms.

\section{Source Area, Source-Basin Length, and Slope}

The plot of source-basin length and the local valley slope at channel heads (Figure 7 (top)) suggests an inverse relationship. Because the error in measuring the slope at channel heads is much less than the error in locating, mapping, and measuring either the source-basin length or source area, we 


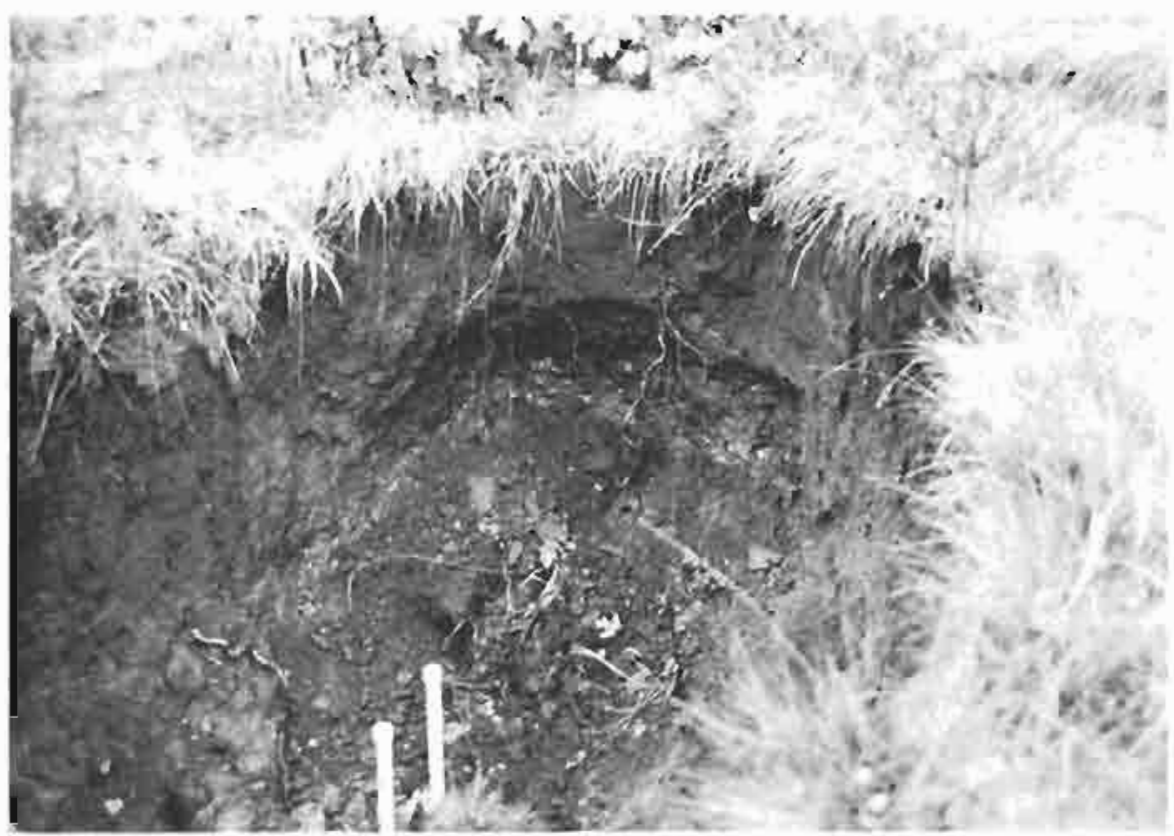

Fig. Sb. Photograph of another abnupt channel head showing seepage coincident with an alcove undermining the headcut. This chamel head advanced approximately 0.4 an upslope during the winter of 1988-1989.

used simple least squares regression of the log-transfomed data to quantify the relations between these parameters. Treating the logarithm of soutce-basin length as the dependent variable, yields an equation for predicting the sourcebasin length $L$ for a known local valley slope $\theta$

$$
L=\lambda \tan \theta^{-0.83} \quad R^{2}=0.47
$$

where $\lambda=67 \mathrm{~m}$.

The scatter plot of source area and the local valley slope at channel heads (Figure 7 (bottom)) also indicates an inverse relationship over a wide range of slopes. Simple least squares linear regression of the log-transformed data, treating source area as the dependent variable, yields

$$
A=\lambda \tan \theta^{-1.65} \quad R^{2}=0.75
$$

where $\lambda$ is $1978 \mathrm{~m}^{2}$. In general, the reduction in source-area size with increasing local valley gradient implies that, all other factors being equal, steeper slopes should have more sources per unit drainage area. Moreover, the source areaslope relation may also provide a physically meaningful method for defining source locations from topographic maps and for use in drainage network simulations.

Combining (9) and (10) implies that

$$
A=0.46 L^{1.99}
$$

or that source area varies approximately as one half the square root of source-basin length. Equation (11a) can be reartanged to give

$$
L=1.48 A^{0.50}
$$

which differs from the relation for drainage networks reported by Hack [1957] in which the coefficient is equal to 1.4 and the exponent is 0.6 . This difference, although small, suggests that source areas are geometrically distinct from downslope drainage basins; the exponent in (11b) also im- plies that the area-length relation for source basins is scale independent.

It is well known that channel slope decreases with increasing drainage area for drainage basins in general [Gilbert, 1877; Leopold and Miller, 1956]. In order to test whether the area-slope relation for channel heads simply reflects this general relation, drainage area and local valley slope were also measured for locations within hollows above channel heads (Figure 8). In general, drainage areas for points upslope of the channel head are wel] below those for channel heads on similar slopes. Furthermore, for several locations upslope of two chanmel heads, drainage area is independent of slope and both channels begin within the variance for channel heads. Both of these channels also end in colluvial fans when the area-slope relation again falls below the lower bound of the scatter for channel beads.

These observations indicate that channel initiation in this area is controlled by hillslope processes rather than network tip extension and suggests that some channels do not connect downstope with the integrated channel network because there is locally insufficient drainage area to support a channel. The unchanneled data within the scatter for channel heads indicates either that the threshold for channel initiation is diffuse or that these locations are susceptible to, but have not as yet experienced, channel incision.

An important component of a widely used model for predicting runoff [Bevin and Kirkby, 1979] is [a(t)/tan $\theta]$ and this parameter is also related to slope for the channel beads in our study area. Because many of the channel heads in the study area are roughly $1 \mathrm{~m}$ across (5) suggests that $a(T)$ is directly proportional to $A$. The scatter plot of $\ln (A / \tan \theta)$ versus $\tan \theta$ indicates that $\ln (A / \tan \theta)$ varies as a function of slope (Figure 9 (top)). Simple least squares linear regression, treating $\ln (A / \tan \theta)$ as the dependent variable, gives

$$
\ln (A / \tan \theta)=12.2-5.4 \tan \theta \quad R^{2}=0.78
$$




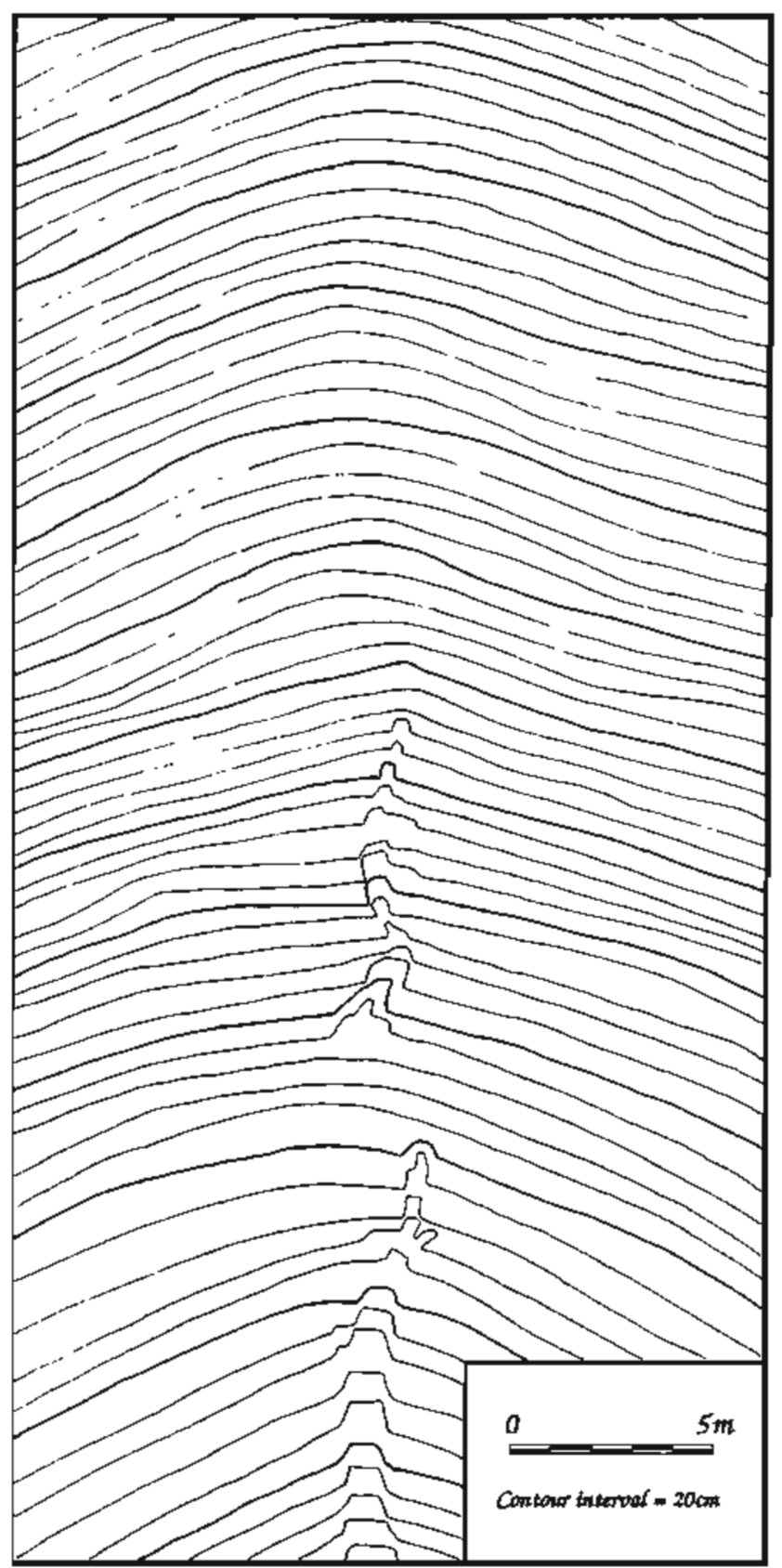

Fig. 6a. Topographic map of channel head $\mathrm{C}$ in Figure 3. The channel begins as a slight depression that grades into an incised channel with 10 cin high banks. The reach immedialely downslope of the channel head is discontinuous.

As discussed above, the source area divided by the width of the depositional zone at the channel head can also be used to estimate $a(T)$ in (4). This quantity is also inversely related to slope (Figure 9 (bottom)) and channel heads located at the base of colluvial deposits have a greater area per unit contour width than for those located within colluvial deposits. These greater values may reflect contributing areas prior to the recent advance of channel heads into the colluvial deposits, suggesting a quantifiable measure of the recent drainage network expansion.

\section{COMPARISON WITH THEORY}

The infinite slope stability model may reasonably approximate conditions operating at landslide-controlled channel beads, but is clearly inadequate to explain either the lowgradient channel heads that appear to be related to seepage erosion or the gradual channel heads apparently controlled by saturation overland flow. Unfortunately, although saturation overland flow and undermining by seepage erosion may be important at many of the channel heads we studied, we know of no available quantitative models of these processes against which to test our field data. We therefore tested only (7).

To obtain the necessary values for $\rho_{s}, K, z, R_{0}, \rho_{n, y}$ and $\phi$ we primarily relied on previous work. Direct shear tests of similar colluvial materials from nearby areas indicate that $\phi$ is approximately $45^{\circ}$ [Reneau et al, 1984]. Reneau et al. [1984] also reported that $\rho_{s}$ is generally 1.5 to $2.0 \mathrm{gm} / \mathrm{cm}^{3}$ for similar soils. Extensive drilling at one location in Tennessee Valley shows that soil depths on sideslopes range from 0.5 to $1.0 \mathrm{~m}$ deep, whereas colluvial deposits can exceed $4 \mathrm{~m}$ depth. Measured soil depths on sideslopes and in hollows from the Lone Tree Creek basin, located roughly $5 \mathrm{~km}$ north of Tennessee Valley, indicate generally similar relations [Dengler et al., 1987; Reneau, 1988] Values for $K$ and $R_{0}$ are particularly difficult to evaluate, however, because the sat-

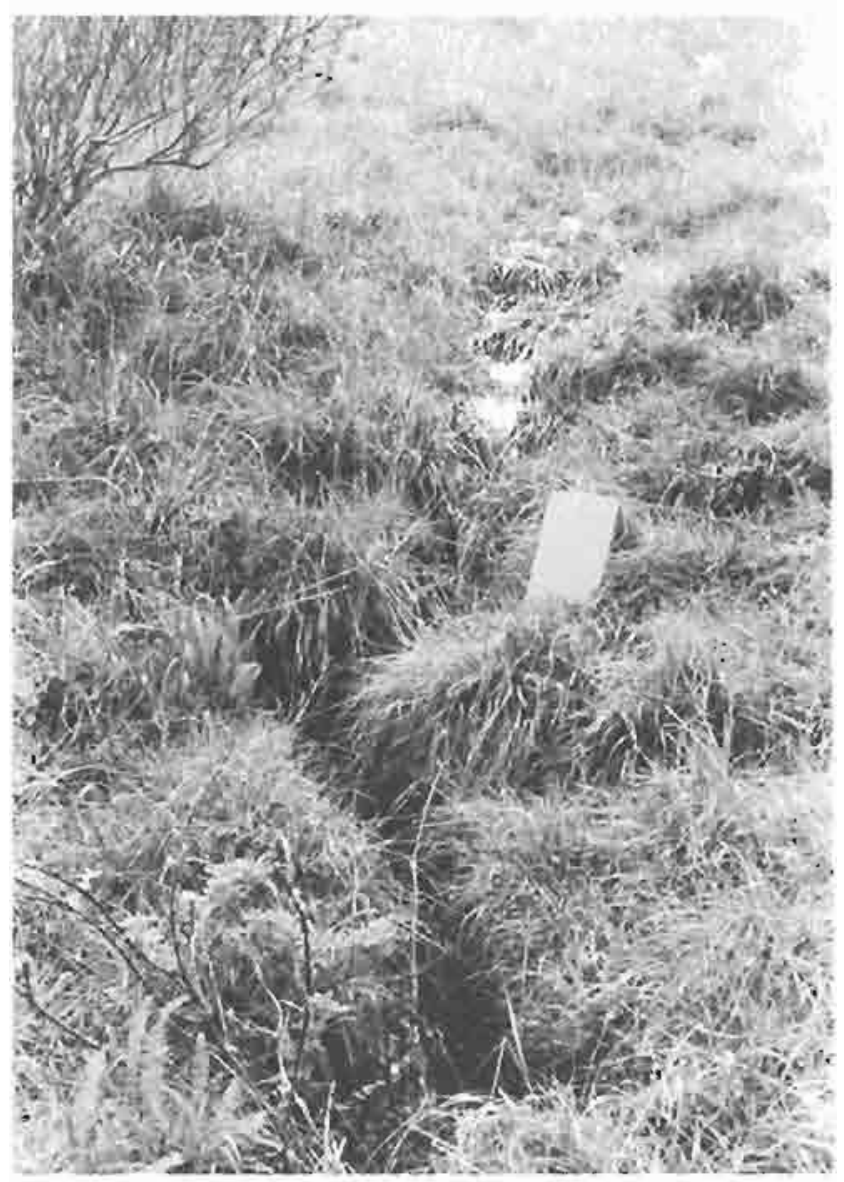

Fig. 6b. Photograpt showing saturation overtand flow spilling into one of the lower channel segments during March 1989. AJthough the channel bead position remained stable, sediment transport was observed in the channel and material was deposited locally as levees and small fars. 

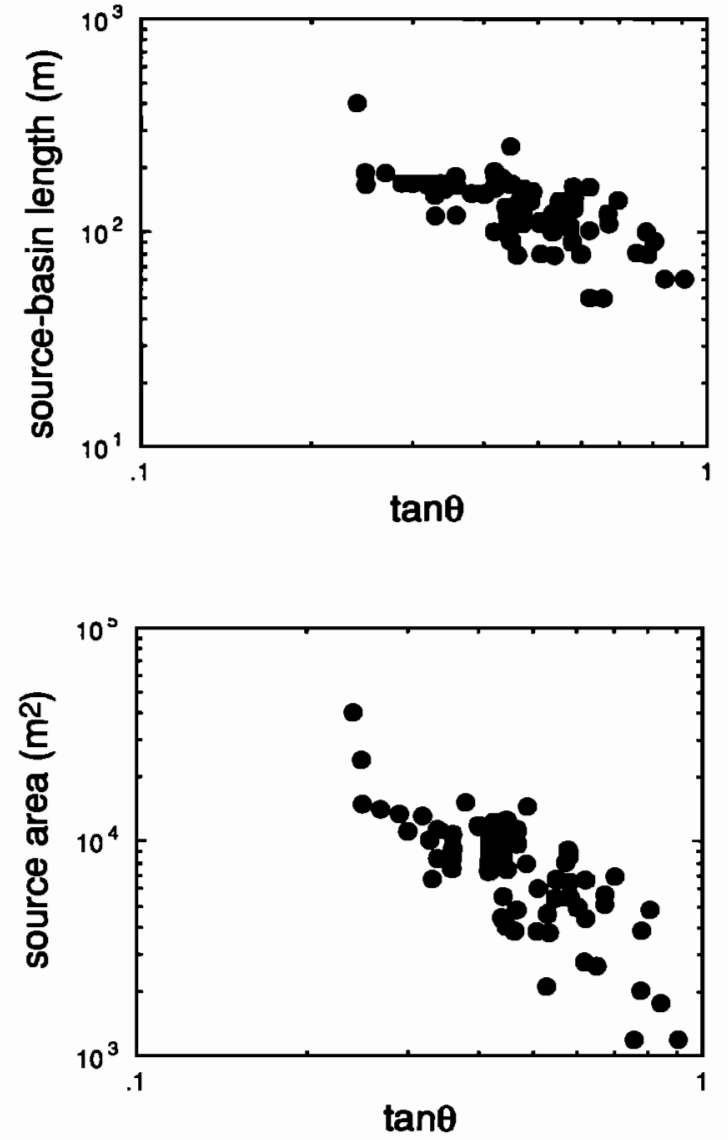

Fig. 7. Scatter plots of (top) source-basin length and (bottom) source area against local valley slope at the channel head $(\tan \theta)$ for source areas in the Tennessee Valley study area.

urated hydraulic conductivity can vary over several orders of magnitude with depth in hollows [Wilson and Dietrich, 1987] and representative values for the time-averaged rainfall intensities, let alone the approximate time intervals, are unknown. Consequently, we have as yet no independent method to independently evaluate either $K$ or $R_{0}$ for each source area. We have therefore calculated the ratio in (7) from the field data. Hence the following analysis can only indicate the general form of the predicted source area-slope relation.

Taking $\phi=45^{\circ}$ and assuming slope failure, (7) can be rewritten as

$$
\frac{\rho_{s} K z}{\rho_{w} R_{0}}=\frac{a(T)}{\sin \theta \cos \theta-\sin ^{2} \theta}
$$

Measurements of $\boldsymbol{A}$ and $\boldsymbol{\theta}$ for the 26 sources within the range indicated by (8) were used to calculate the ratio in (13) for contributing areas equal to the entire source area. Measured values of $A, W_{h}$, and $\theta$ from the 19 channel heads in the appropriate slope range that are located within colluvial deposits were also used to determine solutions for these equations for contributing areas equal to $A / W_{h}$. When the entire source area is used as the contributing area, the field data, averaged over intervals of $\tan \theta$, reasonably follow the trend of the theoretical relationship (Figure 10 (top)) over the entire range of slopes. When the source area divided by the width of colluvial fill at the channel head is used as the contributing area, the field data generally follow the theoret- ical trend (Figure 10 (bottom)), although there is considerable scatter.

The inverse relationship between source area and slope extends to gentle slopes, where landsliding should not be important. On low-gradient slopes in humid regions, erosion by saturation overland flow and by seepage are the most likely channel-initiation mechanisms. Kirkby's [1987] channel-initiation model for saturation overland flow, however, predicts a positive relation between source area and gradient for shallow slopes, rather than the inverse correlation apparent in our data.

Equation (13) suggests that, other factors being equal, increased precipitation would favor smaller source areas, in agreement with field data collected from southern and central California and coastal Oregon [Montgomery and Dietrich, 1988a]. A decrease in rainfall would result in colluvial infilling and downslope displacement of channel heads [Reneau et al., 1986], suggesting that much of the colluvium in hollows may have accumulated as a result of the change to a drier Holocene climate. The present location of many channel heads within colluvial deposits in hollows must have resulted from a subsequent change in the balance between the processes tending to initiate or bury channel heads.

The two most likely hypotheses to explain the apparent recent channel head instability are that the advance of these channel heads into colluvial deposits may be due to an increase in effective soil moisture in the latest Holocene [COHMAP, 1988] or due to the effects of historical cattle grazing. Whether the present location of these channel heads is the result of recent climate change or reflects a historic increase in the erodibility of the soil remains unresolved.

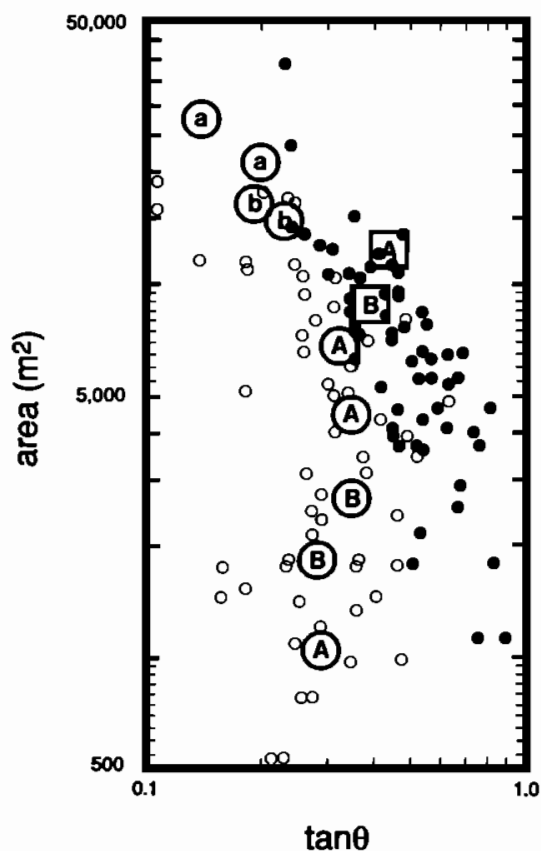

Fig. 8. Plot of drainage area against the local valley gradient for locations in the Tennessee Valley study area. Solid points represent data for channel heads and small open circles represent observations made upslope of the channel heads within source areas. Large open squares are the channel heads for two hollows designated $A$ and $B$. Capital letters in large open circles are the area-slope data for unchanneled areas upslope of these channel heads; lower case letters in large open circles are from unchanneled colluvial fans downslope of these same two channel heads. 

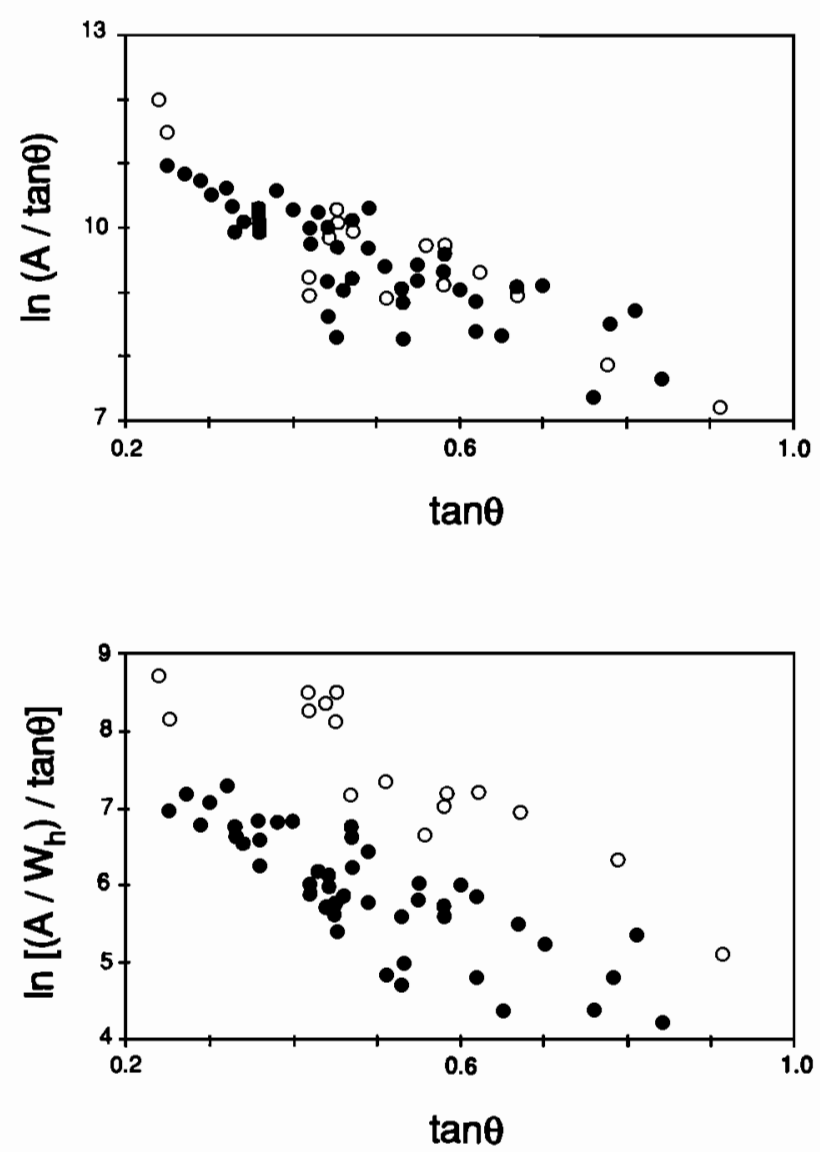

Fig. 9. Plots of the logarithm of contributing area per unit contour length, expressed as (top) In $(A / \tan \theta)$ and (bottom) In $\left.\left[\left(A / W_{h}\right) / \tan \theta\right)\right]$, versus local slope at the channel head $(\tan \theta)$ for the Tennessee Valley study area. In both cases solid points are data from channel heads that are located within colluvial deposits and open circles represent channel heads located at the downslope end of colluvial deposits.

Regardless of the cause, the common extension of the channels into colluvial deposits indicates that this area has undergone, and may be currently undergoing, a change in drainage density that may also have affected both the scatter in the source area-slope data and the relationship itself.

\section{Source Areas and Drainage Density}

Drainage density is a useful measure because it characterizes the scale of landscape forms. Although many studies have concluded that such factors as climate and lithology are related to drainage density, few workers have analyzed the processes by which these factors influence network form. Because many properties of channel networks are relatively invariant, it is possible, using an approximation for source basin geometry based on our data, to express drainage density in terms of source length.

Channel links, their associated areas, and source areas are elementary quantities into which drainage basins can be divided [Shreve, 1969]. Although many workers have investigated link-related properties (for a thorough review see Abrahams [1984]), few [Marcus, 1980; Dietrich et al., 1986; Montgomery and Dietrich, 1988a, b] have investigated source-related ones. Because the average width of exterior basins approximately equals the width of the source area $w_{s}$
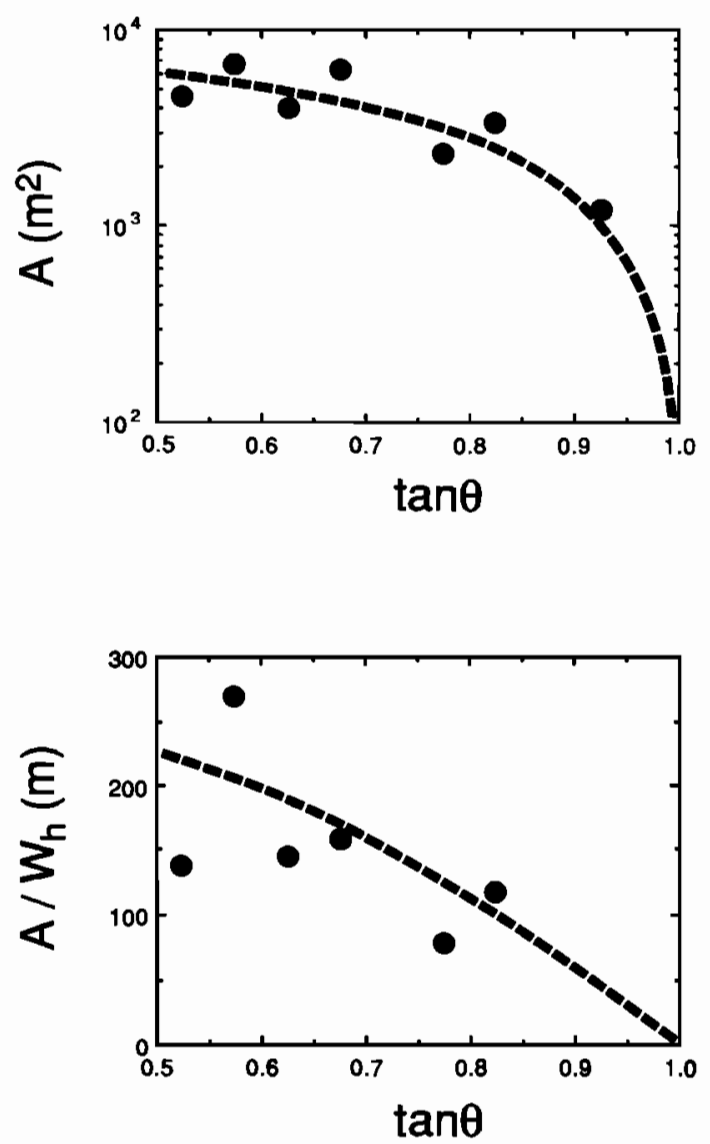

Fig. 10. Plots of (top) source area $(A)$ and (bottom) source area divided by hollow width $\left(A / W_{h}\right)$ against local valley slope $(\tan \theta)$ for the Tennessee Valley data above $\tan \theta=0.5$. In both cases, the solid line represents the fitted relation predicted by (14) and the black circles represent the field data averaged over intervals of $\tan \theta=$ 0.05 .

(Figure 11), the average exterior-link drainage area $a_{e}$ is roughly given by

$$
a_{e}=l_{e} w_{s}+a_{s}
$$

where $l_{e}$ is the mean exterior link link and $a_{s}$ is the mean source area. Furthermore, since

$$
a_{s}=l_{s} w_{s}
$$

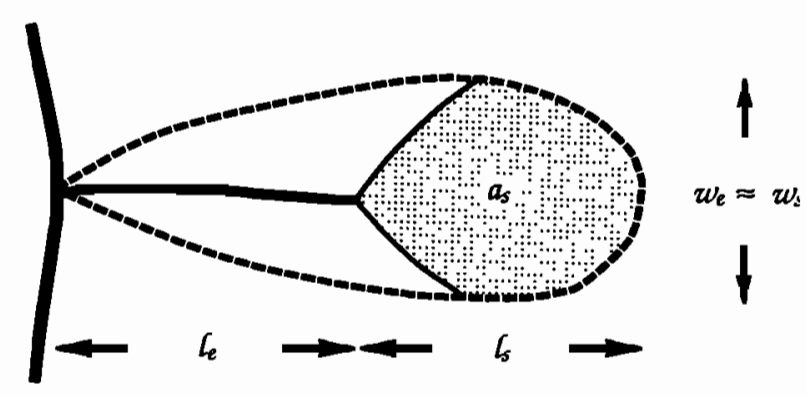

Fig. 11. Schematic map of the relatıon between an exterior link area (outlined by dashed lines) and the source area (stippled pattern) showing their respective lengths and widths. Note that the exterior link area $\left(a_{e}\right)$ is approximately equal to the sum of the source area $\left(a_{s}\right)$ and the product of the source width $\left(w_{s}\right)$ and the exterior link length $\left(l_{e}\right)$. 
TABLE 2. Geometric Properties of the Drainage Network in Tennessee Valley, Califomia

\begin{tabular}{lccccccccccc}
\hline & $l_{s}, m$ & $a_{s}, \mathrm{~m}^{2}$ & $l_{e}, \mathrm{~m}$ & $a_{e}, \mathrm{~m}^{2}$ & $l_{i}, \mathrm{~m}$ & $a_{i}, \mathrm{~m}^{2}$ & $k_{s}$ & $k_{e}$ & $k_{i}$ & $Y$ & $\alpha$ \\
\hline Observed values & 133 & 8,287 & 125 & 16,139 & 89 & 9,764 & 0.47 & 1.03 & 1.23 & 1.95 & 0.71 \\
Values assumed to derive (21) & & & & & & & 0.50 & 1.00 & 1.00 & 2.00 & 1.00 \\
\hline
\end{tabular}

where $l_{s}$ is the mean source-basin length, (14) can be reduced to

$$
l_{e}=(Y-1) l_{s}
$$

where $Y$ is equal to the ratio of the mean exterior-link and source areas, $a_{e} / a_{s}$. Thus defining $k_{s}=a_{s} / l_{s}^{2}$, (14) can be recast in terms of mean source-basin length

$$
a_{e}=Y k_{s} l_{s}^{2}
$$

To relate source-basin length to drainage density, we employ the following definitions, $\alpha=l_{f} / l_{e}, k_{e}=a_{e} / l_{e}^{2}$, and $k_{\text {, }}$ $=a_{i} / l_{i}^{2}$, where $l_{i}$ and $a_{i}$ are the mean interior link length and area, respectively. The drainage density $D$ of a magnitude $\mu$ basin is then given by

$$
D=\frac{\mu+(\mu-1) \alpha}{\left[\mu k_{e}+(\mu-1) k_{i} \alpha^{2}\right] l_{e}}
$$

Substituting (16) into (18) and taking $\mu \gg 1$ gives

$$
D=\frac{1+\alpha}{\left(k_{e}+k_{i} \alpha^{2}\right)(Y-1) l_{s}}
$$

Hence four dimensionless terms $\alpha, k_{e}, k_{i}$, and $Y$ must be specified to relate the mean source-basin length to the drainage density of the entire basin. To our knowledge, no theory is available for predicting them. Empirically, however, many network studies indicate that $k_{e}$ and $k_{i}$ are often close to unity [Abrahams, 1984]. Combining (16) and (17) and the definition of $k_{e}$ yields

$$
k_{e}=\frac{k_{s} Y}{(Y-1)^{2}}
$$

Analysis of source area geometry in many areas (D. R. Montgomery and W. E. Dietrich, manuscript in preparation, 1989 ) indicates that $k_{s} \approx 0.5$, consistent with the relationship given in $(11 b)$ for Tennessee Valley. Consequently, when $k_{e}$ $=1$, then according to (20) $Y=2$. Further, Abrahams [1984] concluded that, although $\alpha$ may vary considerably, it is generally approximately unity. Thus taking $k_{e}=k_{i}=1$, and $\alpha=1$ equation (19) reduces to the simple approximation

$$
D=1 / l_{s}
$$

The mean source-basin length is therefore similar but not equal to both Schumm's [1956] constant of channel mainte- nance and Horton's [1945] length of overland flow. Shreve [1969] pointed out that what Schumm [1956, p. 607] defined as the constant of channel maintenance, the average area draining into a unit length of channel bank, is not mathematically equal to the reciprocal of the drainage density because of the finite area of the source basins. Because Horton's [1945, p. 284] length of overland flow is "approximately equal to half the reciprocal of the drainage density," (21) indicates that it is roughly equal to twice the mean sourcebasin length.

In order to test (19) and (21) against field data, interior and exterior link areas and lengths were measured from field maps of the channel network (Figure 3). There are $9.1 \mathrm{~km}$ of first-order stream channel, including the unconnected channel lengths, and $6.2 \mathrm{~km}$ of higher-order channels within the $2.1 \mathrm{~km}^{2}$ study area, resulting in an overall drainage density of $7.3 \mathrm{~km} / \mathrm{km}^{2}$. The arithmetic mean values of the link parameters were calculated and are presented together with the resulting dimensionless parameters in Table 2 . The drainage densities given by (19) and (21) are given in Table 3. Both (19) and (21) yield drainage densities close to the observed value with the reciprocal of the mean source-basin length giving excellent results. The values tabulated in Table 2 also can be used to show that the geometric assumptions used to derive (14) are reasonable.

For an idealized landscape of uniform geometric and physical properties, drainage density can be directly related to the physical parameters modeled as governing channel initiation on steep hillslopes by combining (7) and (21)

$$
D=\frac{w_{s} \rho_{w} R_{0}}{W^{*} \rho_{s} K z \sin \theta \cos \theta}\left[1-\left(\frac{\tan \theta}{\tan \phi}\right)\right]^{-1}
$$

where $W^{*}$ is either the hollow width at the channel head, $W_{h}$ or channel width $W_{c h}$. According to (22), drainage density increases with decreasing saturated hydraulic conductivity and frictional strength of the soil and increasing precipitation, local valley gradient at the channel head, and width of the source area relative to the width of the depositional zone or channel head. Although some evidence exists to support

\begin{tabular}{|c|c|c|c|}
\hline Equation & $\begin{array}{l}\text { Expression for } \\
\text { Drainage Density }\end{array}$ & $\begin{array}{c}\text { Drainage Density } \\
\text { Calculated Using } \\
\text { Values From Table } \\
2, \mathrm{~km} / \mathrm{km}^{2}\end{array}$ & $\begin{array}{c}\text { Percent of } \\
\text { Observed } \\
\text { Drainage Density }\end{array}$ \\
\hline (19) & $\frac{1+\alpha}{\overline{\left(k_{e}+k_{j} \alpha^{2}\right)(Y-1) l_{s}}}$ & - & 112 \\
\hline (21) & $1 / l_{s}$ & 7.5 & 103 \\
\hline
\end{tabular}
the dependence on precipitation, conductivity, and gradient [Abrahams, 1984], we are aware of no data on the influence of soil strength. Furthermore, the ratio of widths indicates that the drainage density will be larger where the depositional zones or channel heads tend to be narrow.

TABLE 3. Drainage Density Calculations for Tennessee Valley, California 


\section{ConClusions}

Both source-basin length and area vary inversely with the local valley gradient at the channel head. Although both relations are subject to considerable scatter, similar relations which appear to vary systematically with annual precipitation have been found in other humid landscapes [Montgomery and Dietrich, 1988a]. The contributing area per unit contour length at channel heads divided by slope also varies as a function of the local valley slope. Consequently, a single value for the source area or the contributing area per unit contour length can not be satisfactorily used to position sources in network simulations.

Many channels in the study area do not connect to the downslope drainage network, indicating that channel head locations in the study area are controlled by hillslope processes rather than headward channel network extension. For steep slopes, the form of the observed relations between drainage area and the local valley gradient at the channel head supports the general form predicted by a model for channel initiation due to soil instability resulting from the convergence of shallow subsurface flow. Field observations also suggest that, in general, channel head locations may be controlled by landsliding on steeper slopes and by seepage erosion and saturation overland flow on gentler ones. Furthermore, the inverse of the mean source-basin length provides an excellent estimate of drainage density. Together these findings demonstrate the significance of the channel head as a crucial linkage between hillslopes and channel networks, and point to the need for greater understanding of the controls on channel initiation and channel head locations.

\section{Notation}

$A$ source area, $\mathrm{m}^{2}$.

$a(t)$ contributing drainage per unit contour length, $\mathrm{m}$.

$a(T)$ contributing drainage area per unit contour length for channel maintaining events, $\mathrm{m}$.

$a_{e}$ mean exterior link drainage area, $\mathbf{m}^{2}$.

$a_{i}$ mean interior link drainage area, $\mathrm{m}^{2}$.

$a_{s}$ mean source area, $\mathrm{m}^{2}$.

$D$ drainage density, $\mathrm{m} / \mathrm{m}^{2}$.

$h$ thickness of saturated soil, $\mathrm{m}$.

$K$ saturated hydraulic conductivity, $\mathrm{m} / \mathrm{s}$.

$k_{e}$ ratio of mean exterior link area to the square of mean exterior link length, $a_{e} / l_{e}^{2}$.

$k_{i} \quad$ ratio of mean interior link area to the square of mean interior link length, $a_{i} / l_{i}^{2}$.

$k_{s} \quad$ ratio of mean source area to the square of mean source-basin length, $a_{s} / l_{s}^{2}$.

$L$ source-basin length, $m$.

$l_{e}$ mean exterior link length, $\mathrm{m}$.

$l_{i}$ mean interior link length, $\mathrm{m}$.

$l_{s}$ mean source-basin length, $\mathrm{m}$.

$Q$ discharge per unit contour length, $\mathrm{m}^{2} / \mathrm{s}$.

$R_{0}$ rainfall rate, $\mathrm{m} / \mathrm{s}$.

$W_{c h}$ width of the channel head, $m$.

$W_{h}$ width of the depositional zone at the channel head, m.

$W^{*}$ contour length through which throughflow is routed, m.

$w_{s}$ mean source width, $m$.

$Y$ ratio of mean exterior link area to mean source area, $a_{e} / a_{s}$

$z$ vertical soil thickness, $m$.

$\alpha$ ratio of the mean interior- to mean exterior-link length, $l_{i} / l_{e}$.

$\lambda$ regression constant, units are variable and given in text.

$\mu$ drainage basin magnitude.

$\phi$ soil angle of internal friction, degrees.

$\rho_{s}$ saturated bulk density of soil, $t / \mathrm{cm}^{3}$.

$\rho_{w}$ bulk density of water, $t / \mathrm{cm}^{3}$.

$\theta$ local hillslope gradient at the channel head, degrees.

Acknowledgments. This study was funded by NSF grant EAR8451175 and received some matching funds from the Weyerhaueser Corperation. We are indebted to Anne Bikle, Marc Caruso, Anna Coelo-Netto, Dean Kinerson, Yutaka Komatsu, Deb Loewenherz, Jim McKean, and Kent Rich for providing field assistance and/or logistical support. Tom Dunne, Keith Loague, Steve Reneau, and several anonymous reviewers provided valuable comments on drafts of this manuscript and Ron Shreve gave it a thorough review. Don Bain gave us access to the Computing Facility of the University of Califormia Berkeley Department of Geography, and the Golden Gate National Recreation Area gave permission for field work within their jurisdiction.

\section{REFERENCES}

Abrahams, A. D., Channel networks, a geomorphological perspective, Water Resour. Res., 20, 161-188, 1984.

Beven, K. J., and M. J. Kirkby, A physically based variable contributing area model of basin hydrology, Hydrol. Sci. Bull., 24(1), 43-69, 1979.

Coates, D. R., Quantitative geomorphology of small drainage basins in Southern Indiana, Tech. Rep. 10, Dep. of Geol., Columbia Univ., New York, 1985.

Cooperative Holocene Mapping Project (COHMAP), Climatic changes of the last 18,000 years: Observations and model simulations, Science, 241, I043-1052, 1988.

Dengler, L., and D. R. Montgomery, Estimating the thickness of colluvial fill in unchanneled valleys from surface topography, Bull. Assoc. Eng. Geol., 26, 333-342, 1989.

Dengler, L., A. K. Lehre, and C. J. Wilson, Bedrock geometry of unchannelized valleys, IAHS Publ., I65, 81-90, 1987.

Dietrich, W. E., and T. Dunne, Sediment budget for a small catchment in mountaneous terrain, Z. Geomorph., Suppl. 29 191-206, 1978.

Dietrich, W. E., C. J. Wilson, and S. L. Reneau, Hollows, colluvium, and landslides in soil-mantled landscapes, in Hillslope Processes, edited by A. D. Abrahams, pp. 361-388, Allen and Unwin, London, 1986.

Dietrich, W. E., S. L. Reneau, and C. J. Wilson, Overview: "Zero-order basins" and problems of drainage density, sediment transport and hillslope morphology, IAHS Publ., 165, 49-59, 1987.

Dunne, T., Field studies of hillslope flow processes, in Hillslope Hydrology, edited by M. J. Kirkby, pp. 227-293, John Wiley and Sons, New York, 1978.

Dunne, T., Formation and controls of channel networks, Prog. Phys. Geogr., 4, 211-239, 1980.

Freeze, R. A., A stochastic conceptual analysis of one-dimensional groundwater flow in non-uniform homogeneous media, Water Resour. Res., 11, 725-741, 1975.

Gilbert, G. K., Geology of the Henry Mountains, 160 pp., U.S. Geological Survey, Washington, D. C., 1877.

Hack, J. T., Studies of longitudinal stream profiles in Virginia and Maryland, U.S. Geol. Surv. Prof. Pap., 294-B, 97 pp., 1957.

Hack, J. T., Geomorphology of the Shenandoah Valley, Virginia and West Virginia, and origin of the residual ore deposits, U.S. Geol. Surv. Prof. Pap., 484, 84 pp., 1965.

Hack, J. T., and J. C. Goodlett, Geomorphology and forest ecology of a mountain region in the central Appalachians, U.S. Geol. Surv. Prof. Pap., 347, 64 pp., 1960.

Horton, R. E., Erosional development of streams and their drainage basins; Hydrophysical approach to quantitative morphology, Geol. Soc. Am. Bull., 56, 275-370, 1945. 
Iida, T., A hydrological method of estimation of the topographic effect on the saturated throughflow, Trans. Jpn. Geomorphol. Union, 5(1), 1-12, 1984.

Kirkby, M. J., Modelling some influences of soil erosion, landslides and valley gradient on drainage density and hollow development, in Geomorphological Models, Catena Supplement 10, edited by F. Ahnert, pp. 1-14, Catena Verlag, Cremlingen, W. Germany, 1987.

Kirkby, M. J., and R. J. Chorley, Throughflow, overland flow and erosion, Bull. Int. Assoc. Sci. Hydrol., 12, 5-21, 1967.

Leopold, L. B., and J. P. Miller, Ephermeral streams-hydraulic factors and their relation to the drainage net, U.S. Geol. Surv. Prof. Pap., 282A, 36 pp., 1956.

Marcus, A., First-order drainage basin morphology-definition and distribution, Earth Surf. Processes Landforms, 5, 389-398, 1980.

Mark, D. M., Relations between field-surveyed channel networks and map-based geomorphic measures, Inez, Kentucky, Ann. Assoc. Am. Geogr., 73(3), 358-372, 1983.

Maxwell, J. C., Quantitative geomorphology of the San Dimas Experimental Forest, California, Tech. Rep. 19, Dep. of Geol., Columbia Univ., New York, 1960.

Montgomery, D. R., and W. E. Dietrich, Where do channels begin?, Nature, 336, 232-234, $1988 a$.

Montgomery, D. R., and W. E. Dietrich, The relationship between source area size and drainage density (abstract), Eos Trans. AGU, 69(44), 1224, 1988b.

Morisawa, M. E., Accuracy of determination of stream lengths from topographic maps, Eos Trans. AGU, 38, 86-88, 1957.

Rantz, S. E., Average annual precipitation and runoff in north coastal California, U.S. Geol. Surv. Hydrol. Atlas 298, scale $1: 1,000,000$, Washington, D.C., 1968.

Reneau, S. L., Depositional and erosional history of hollows: Application to landslide location and frequency, long-term erosion rates and the effects of climatic change, Ph.D. dissertation, 328 pp., Univ. of Calif., Berkeley, 1988.

Reneau, S. L., W. E. Dietrich, C. J. Wilson, and J. D. Rogers, Colluvial deposits and associated landslides in the northern San Francisco Bay area, California, USA, in Proceedings of IVth International Symposium on Landslides, pp. 425-430, Interna- tional Society for Soil Mechanics and Foundation Engineering, Toronto, Ontario, Canada, 1984

Reneau, S. L., W. E. Dietrich, R. I. Dorn, C. R. Berger, and M. Rubin, Geomorphic and paleoclimatic implications of latest Pleistocene radiocarbon dates from colluvium-mantled hollows, California, Geology, 14, 655-658, 1986.

Schumm, S. A., Evolution of drainage systems and slopes in badlands at Perth Amboy, New Jersey, Geol. Soc. Am. Bull., 67, 597-646, 1956.

Selby, M. J., Hillslope Materials \& Processes, 264 pp., Oxford University Press, New York, 1982.

Shreve, R. L., Statistical law of stream numbers, J. Geol., 74, 17-37, 1966.

Shreve, R. L., Stream lengths and basin areas in topologically random channel networks, J. Geol., 77, 397-414, 1969.

U.S. Department of Agriculture, Soil Survey of Marin County, California, Soil Conservation Service in cooperation with United States Department of the Interior, National Park Service, and University of California Agricultural Experiment Station, 229 pp., Washington, D. C., 1985.

Wahrhaftig, C., Structure of the Marin Headlands Block, California: A progress report, in Franciscan Geology of Northern California, edited by M. C. Blake, Jr., vol. 43, pp. 31-50, Society of Economic Paleontologists and Minerologists, Pacific Coast Section, Bakersfield, Calif., 1984.

Wilson, C. J., and W. E. Dietrich, The contribution of bedrock groundwater flow to storm runoff and high pore pressure development in hollows, IAHS Publ., 165, 49-59, 1987.

Wilson, C. J., W. E. Dietrich, J. McKean, M. Alavi, and T. N. Narasimhan, Predicting pore pressure response in small basins with analytic models (abstract), Geol. Soc. Am. Abstr. Programs, $19,892,1987$.

W. E. Dietrich and D. R. Montgomery, Department of Geology and Geophysics, University of California, Berkeley, CA 94720.

(Received October 31, 1988; revised April 20, 1989; accepted April 25, 1989.) 